\title{
Career Success Skills - Stronger Together = Faculty, Professionals, and Students
}

\author{
AAA ELS 2020
}

Terry Campbell, Christopher Cook, and Bree Josefy

\section{$\Psi$}

KELLEY SCHOOL OF BUSINESS 


\section{VUCA finally arrived for being stronger together - 2020}

- In a world marked by VUCA [Volatility, Uncertainty, Complexity, and Ambiguity] and intensified with a pandemic, graduate accounting students are faced with finding career success. We have co-taught the Career Success Skills for MSA students for several years including an emphasis on VUCA; but, this is the first pandemic. We use less than two weeks just before the academic year starts to immerse the students as graduate accounting students.

- We work full-time for the 9 days to help build professionalism, personal growth, and a presentation worthy to present to senior professionals

\section{ЏI INDIANA UNIVERSITY}




\section{Faculty, professionals, and students interact to learn rapidly and deeply}

- Key issues discussed include, but are not limited to, selection of topics, coordination across sections [3], synthesis with sections together, bringing selected professionals together with the class for interactions, interacting with career services staff, designing / delivering a final integrated assignment to external professionals -just nine days from starting the graduate program. professionally.

- More than 24 professionals interact with the students at various times during the course

- Topics begin with just a few words - and students must discover sufficient breadth - or too much - and narrow down to what is needed to present to professionals where the end result is to ask for additional resources to investigate further or to implement a test run 


\section{The goal is the beginning of a personal and professional transformation}

- Learning outcomes: Students will interact with external professionals in a variety of settings. Students will know themselves and others in order to recognize, appreciate, and act upon their individual differences Students will deliver a professional topic to a panel of external professionals. Overall, the goal is to provide an opportunity to transform personally and professionally.

- We challenge the students for finding their version of 'Courageous Leadership'

https://iupress.org/9780253019226/courageous-leadershiprevised-edition/ 


\section{We assert the courageous leaders are vital to any organization/ career}

In this essential and very readable guide to career success the Kelley Way, leaders from the top ranked business school in the country reveal the cornerstone for advancement in businesses-courageous leadership. "What organizations really want," the authors announce, "is courageous, ethical leaders who can identify and solve complex problems under conditions of uncertainty, motivate others to perform at high levels, and consistently achieve superior organizational outcomes on schedule within resource constraints." In these pages, the principles and attributes of a courageous leader are laid out, depicting an effective communicator and motivator, selflearner, critical thinker in the face of complex problems, and a savvy participant in team and organizational environments with a rock solid ethical foundation. https://iupress.org/9780253019226/courageous-leadership-revised-edition/

\section{TIT INDIANA UNIVERSITY}




\section{Our approach matches up to the AICPA and the IMA competency frameworks}

Emphasis on the IMA Management Accounting Competencies AICPA Core Competency Framework and its defined set of skill-based competencies - These complementary 'courses' address nearly every aspect of the AICPA Core Competence Framework. Specifically, they focus on:

- Global and industry perspectives - Identify the unique global and industry factors, and analyze the related risks and opportunities and their impact on an organization.

- Research - Identify, access and apply relevant professional frameworks, standards and guidance, as well as other information for analysis and to make informed decisions.

- In a closer examination of the other competencies, we find that we have had topics projects on each and every competency. Of course, not every student gets the same elements but collectively, we are able to confirm that the students have covered every topic in the frameworks.

We start with the Hard, Harder, Hobby assignment where the 'soft skills' are the harder ones! We build from that to find each unique personal development plan 
From the hard, harder, and hobby assignments, we lead the students:

through the topics in the textbook - See Table of Contents here through the team building process

through the personal identification of personality and the need for recognizing, appreciating, and acting on differences through a rigorous research and presentation process FOR PRESENTATION TO INTERESTED PROFESSIONALS
About the Authors

Acknowledgments

Preface: A Stake in the Ground

7

10

PART I. COURAGEOUS LEADERSHIP

Chapter 1. It's about the Pack!

Chapter 2. A Philosophy of Courageous Leadership

Chapter 3. Leadership Power, Theories, and Styles

Chapter 4. Four Common Business Leadership Situations

PART II. THE INNER SELF

Chapter 5. Understanding Others and Yourself

Chapter 6. Business Ethics: The Organization's Inner Self

Chapter 7. Motivating Others and Yourself

Chapter 8. Fostering Growth in Others and Yourself

PART III. YOUR PERSONAL CAREER-SUCCESS TOOLKIT

Chapter 9. Critical Thinking in Identifying and Solving Complex Problems 162

Chapter 10. Self-Learning

Chapter 11. Effective Communication

Chapter 12. Becoming a Talent That Fits: Combining Leadership and Technical Skills

PART IV. UNDERSTANDING THE ORGANIZATIONAL ENVIRONMENT

Chapter 13. Organizational Control and Measurement: What Gets Measured Gets Done

Chapter 14. Teams and Teamwork

Chapter 15. Organizational Savvy

Chapter 16. Customer/Client Interface: The Bottom Line Is about the Top Line

Conclusion: Putting It All Together

Appendix A. Written Communication for Credible and Effective Leaders Appendix B. A Brief Marketing Skills Tutorial

Appendix C. Using MBTI SpeedReading to Assess Customer/Client Preferred Behaviors Appendix D. Activity-Based Costing

Appendix E. Economic Value Added (EVA)

Notes

Bibliography 